Article

\title{
Interactive Effects of Light and Melatonin on Biosynthesis of Silymarin and Anti-Inflammatory Potential in Callus Cultures of Silybum marianum (L.) Gaertn.
}

\author{
Muzamil Shah ${ }^{1,+}$, Muhammad Asad Ullah ${ }^{1,+}$, Samantha Drouet ${ }^{2,+}$, Muhammad Younas ${ }^{1}$, \\ Duangjai Tungmunnithum ${ }^{2,3,4}\left(\mathbb{D}\right.$, Nathalie Giglioli-Guivarc' ${ }^{5}{ }^{5}$, Christophe Hano ${ }^{2,4, *(\text { i) }}$ \\ and Bilal Haider Abbasi 1,2,3,5,*(D) \\ 1 Department of Biotechnology, Quaid-i-Azam University, Islamabad-45320, Pakistan; \\ muzamilshah1989@gmail.com (M.S.); asad_ullah8050@yahoo.com (M.A.U.); pk.younas@gmail.com (M.Y.) \\ 2 Laboratoire de Biologie des Ligneux et des Grandes Cultures (LBLGC), INRA USC1328, \\ Université d'Orléans, 45067 Orléans CEDEX 2, France; samantha.drouet@univ-orleans.fr (S.D.); \\ duangjai.tun@mahidol.ac.th (D.T.) \\ 3 COSM'ACTIFS, Bioactifs et Cosmétiques, CNRS GDR3711, 45067 Orléans CEDEX 2, France \\ 4 Department of Pharmaceutical Botany, Faculty of Pharmacy, Mahidol University, 447 Sri-Ayuthaya Road, \\ Rajathevi, Bangkok 10400, Thailand \\ 5 EA2106 Biomolecules et Biotechnologies Vegetales, Universite Francois-Rabelais de Tours, 37000 Tours, \\ France; nathalie.guivarch@univ-tours.fr \\ * Correspondence: christophe.hano@univ-orleans.fr or hano@univ-orleans.fr (C.H.); \\ bhabbasi@qau.edu.pk (B.H.A.); Tel./Fax: +33-237-309-753 (C.H.); +33-77-698-41-48 (B.H.A.) \\ + These authors contributed equally to this work.
}

Received: 28 February 2019; Accepted: 27 March 2019; Published: 27 March 2019

check for updates

\begin{abstract}
Silybum marianum (L.) Gaertn. is a well-known medicinal herb, primarily used in liver protection. Light strongly affects several physiological processes along with secondary metabolites biosynthesis in plants. Herein, S. marianum was exploited for in vitro potential under different light regimes in the presence of melatonin. The optimal callogenic response occurred in the combination of $1.0 \mathrm{mg} / \mathrm{L} \alpha$-naphthalene acetic acid and $0.5 \mathrm{mg} / \mathrm{L}$ 6-benzylaminopurine under photoperiod. Continuous light associated with melatonin treatment increased total flavonoid content (TFC), total phenolic content (TPC) and antioxidant potential, followed by photoperiod and dark treatments. The increased level of melatonin has a synergistic effect on biomass accumulation under continuous light and photoperiod, while an adverse effect was observed under dark conditions. More detailed phytochemical analysis showed maximum total silymarin content $(11.92 \mathrm{mg} / \mathrm{g}$ dry weight (DW)) when placed under continuous light $+1.0 \mathrm{mg} / \mathrm{L}$ melatonin. Individually, the level of silybins (A and B), silydianin, isolsilychristin and silychristin was found highest under continuous light. Anti-inflammatory activities were also studied and highest percent inhibition was recorded against 15-lipoxygenase (15-LOX) for cultures cultivated under continuous light $(42.33 \%)$. The current study helps us to better understand the influence of melatonin and different light regimes on silymarin production as well as antioxidant and anti-inflammatory activities in S. marianum callus extracts.
\end{abstract}

Keywords: Silybum marianum (L.) Gaertn.; light regimes; melatonin; antioxidant; phenolics; flavonoids; silymarin; anti-inflammatory 


\section{Introduction}

Silybum marianum (L.) Gaertn. (Family Asteraceae), commonly called milk thistle, is an important medicinal herb with a potent hepatoprotective activity [1]. The annual average sale of $S$. marianum is about 8 billion USD and the demand per year varies from 18 to 20 tons [2]. Silymarin is the prominent component in S. marianum, which is an isomeric mixture of several compounds including the flavonolignans silybins, silychristin, isosilybins, and silydianin associated with the flavonoid taxifolin. Due to its well described free radical scavenging capacity, silymarin can protect human hepatic tissues by neutralizing the effect of oxidative damage [3]. Studies from in vivo and in vitro animal models suggest the protective role of silymarin on hepatic cells from toxin [4]. A variety of active ingredients are produced in plants during development in which phenolic compounds have a distinct identity as antioxidant agents [5]. Redox properties of the compounds are generally responsible for antioxidant activity [6], which enable them to act as hydrogen-atom donors or reducing agents [7]. Silymarin is known to exhibit various medicinal properties including antiviral, anti-diabetic, anticancer, anti-inflammatory, anti-arthritic, antioxidant and immunomodulatory [2,8-12]. Additionally, silymarin extract has also been shown to be effective in treating non-alcoholic fatty liver disorder (NAFLD), obsessive-compulsive disorder (OCD) and $\beta$-thalassemia [13-15]. Anti-inflammatory activities of plant extracts are usually assessed by measuring \% inhibition of COX-1 (cyclooxygenase 1), COX-2 (cyclooxygenase 2), sPLA2 (secretory phospholipase A2) and 15-LOX (15-lipoxygenase). Cyclooxygenases (COXs) are endogenous enzymes that help to maintain tissue homeostasis of kidney, platelets, gastrointestinal tract and expressed in different types of cancers [16]. COXs are the key player in inflammation process and are usually the main target for development of NSAIDs (non-steroidal anti-inflammatory drugs). COX-1 is known as a house-keeping enzyme, whereas COX-2 produces prostaglandin E2 which is an endogenous pain-producing molecule. Some anti-inflammatory drugs consists of the molecular mechanism that inhibit both COX-2 and COX-1 enzymes. So, these drugs which inhibit both COX-1 and COX-2 enzymes can cause undesirable side effects such as renal dysfunction and/or gastrointestinal bleeding. Thus, researchers nowadays seek better candidates that can inhibit only COX-2 expression for drug discovery and development [17]. The current review on chemistry, pharmacological activities and nutraceutical uses of $S$. marianum in liver diseases reported that silymarin, a major phytochemical compound from S. marianum, exhibited both anti-inflammatory and immunomodulatory potentials by inhibiting NF- $\mathrm{kB}$ pathway [1]. Moreover, silymarin and the S. marianum preparations show a low level of drug interaction [1]. Interestingly, the review on the effect of S. marianum in metabolic syndrome on both animal models and clinical trials conducted on humans suggested that silymarin has potential to be an alternative choice for treatment of metabolic syndrome disease [18]. Plants are primary source of compounds that inhibit these key enzymes during inflammation process by acting as natural inhibitors $[19,20]$. Multiple biotic as well as abiotic elicitors have previously been employed in vitro in several medicinal plant species to increase the content of secondary metabolites. Elicitors alter plant metabolism by provoking physiological cascades which leads to enhanced biosynthesis of phytochemicals [21,22]. As a chief abiotic elicitor, light affects various physiological processes (such as, photosynthesis), hence morphogenesis, development and growth of several medicinal plants in vitro $[23,24]$.

Melatonin ( $N$-acetyl-5-methoxytryptamine), discovered initially in vertebrates, is a naturally occurring indole amine [25], which, after its detection as phytohormone, has also been spotted in various plant species (oats, rice, corn, barley and wheat) [26-29]. Manchester et al. [29] reported higher concentration of melatonin in white and black seeds of mustard as compared to the level in the blood of vertebrates. Melatonin higher levels comparatively in plants are assumed to be plants compensatory response as, unlike animals, they are devoid of mobility to cope with extreme environments. Numerous reports indicate the role of melatonin in root development, division of cells [30], photoperiod dependent processes and regulation of circadian rhythms [31-33]. Moreover, due to similarities in structure, it has also been used as a substitute to IAA (Indole-3-acetic acid) [34]. Photoperiod influences the endogenous melatonin level and elevated level of melatonin have been 
detected during the dark in plants [35]. The current study was designed to explore the interactive effect of light and melatonin on silymarin biosynthesis in S. marianum callus cultures and its antioxidant and anti-inflammatory potential.

\section{Results and Discussion}

\subsection{Interactive Effect of Light and Melatonin on Biomass Accumulation}

Plants have the capacity to perceive and process information for optimum growth and development from their biotic and abiotic environments [36]. As an abiotic elicitor, light has a vital role in a plant's growth and development by regulating indigenous metabolic activities and maintaining hormonal balance [35]. On the other hand, melatonin is known to provide defense against biotic and abiotic stressors [37,38]. The current study investigated the effect of melatonin on callus cultures of $S$. marianum placed under different light regimes. Application of different melatonin concentrations under three light regimes (dark $(24 \mathrm{~h})$, photoperiod $(16 \mathrm{~h} / 8 \mathrm{~h})$ and continuous white light $(24 \mathrm{~h})$ ) was studied for optimal biomass production. Highest biomass production (15.9 g/L dry weight (DW)) occurred in callus culture treated with $1.0 \mathrm{mg} / \mathrm{L}$ melatonin grown under continuous white light (Table 1), while lowest biomass accumulation $(7.54 \mathrm{~g} / \mathrm{L})$ was noted in the dark grown cultures with $10.0 \mathrm{mg} / \mathrm{L}$ melatonin. Under the photoperiod cycle, highest biomass accumulation (14.37 mg/L) happened at $0.5 \mathrm{mg} / \mathrm{L}$ melatonin (Figure 1). Overall, continuous light and photoperiod showed a profound effect with moderate melatonin concentrations, whereas an increase in melatonin concentration exhibited inhibitory effects on biomass accumulation in the dark grown cultures. Similarly, study conducted by Fazal et al. [39] indicated that moderate concentration of exogenous melatonin treatment produces optimum results in callus culture of P. vulgaris. Khan et al. [40] also studied the interrelating effect of light and melatonin in callus cultures of Fagonia indica for enhanced production of anticancer compounds. The results of their study suggested that continuous white light with melatonin is most effective as compared to other light treatments. Adil et al. [41] also concluded that combined treatment of melatonin and continuous light display optimum biomass and secondary metabolites accumulation in adventitious roots culture of $W$. somnifera.

Table 1. Interactive effect of different light regimes and melatonin treatments on biomass production in callus culture of $S$. marianum.

\begin{tabular}{|c|c|c|c|c|c|c|}
\hline \multirow{2}{*}{$\begin{array}{c}\text { Treatment } \\
\text { Melatonin }(\mathrm{mg} / \mathrm{L})\end{array}$} & \multicolumn{2}{|c|}{ Dark (24 h) } & \multicolumn{2}{|c|}{ Photoperiod (16 h/8 h) } & \multicolumn{2}{|c|}{ Continuous Light (24 h) } \\
\hline & FW (g/L) & DW (g/L) & FW (g/L) & DW (g/L) & FW (g/L) & DW (g/L) \\
\hline Control & $170.47 \pm 3.83^{\mathrm{d}}$ & $10.74 \pm 0.38$ bc & $188.9 \pm 5.38 \mathrm{~cd}$ & $11.27 \pm 0.64$ bc & $215.4 \pm 4.07^{c}$ & $12.56 \pm 0.50^{b}$ \\
\hline 0.5 & $159.9 \pm 5.20 \mathrm{de}$ & $13.11 \pm 1.37$ ab & $177.14 \pm 4.86^{\mathrm{d}}$ & $14.37 \pm 0.13^{\mathbf{a b}}$ & $266.7 \pm 7.6^{\mathrm{ab}}$ & $14.29 \pm 0.83^{\mathrm{ab}}$ \\
\hline 1.0 & $135.78 \pm 7.78$ e & $10.79 \pm 0.90 \mathbf{b c}$ & $205.88 \pm 3.42^{c}$ & $13.87 \pm 0.92 \mathbf{a b}$ & $299.3 \pm 6.57^{\mathbf{a}}$ & $15.96 \pm 0.68^{\mathbf{a}}$ \\
\hline 2.5 & $131.58 \pm 6.03 \mathrm{e}$ & $10.66 \pm 0.49$ bc & $175.01 \pm 4.46^{\mathrm{d}}$ & $10.39 \pm 0.50 \mathbf{b c}$ & $204.3 \pm 9.72 \mathrm{c}$ & $12.57 \pm 0.37^{\mathbf{b}}$ \\
\hline
\end{tabular}

Values are means \pm SD from triplicates. Columns with similar alphabets are not significantly different $(p<0.05)$. $(\mathrm{FW}=$ fresh weight; $\mathrm{DW}=$ dry weight).
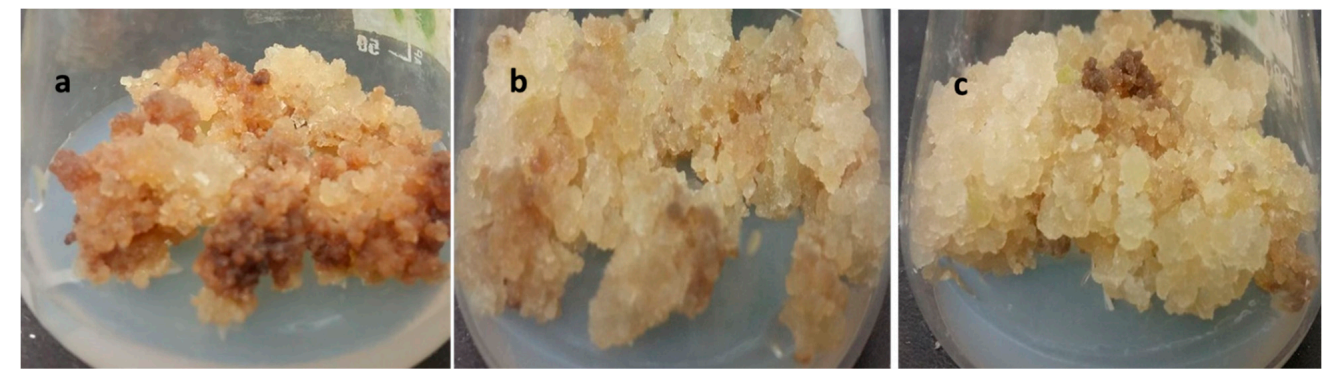

Figure 1. Effect of light and melatonin on S. marianum callus morphology. (a) Dark $+0.5 \mathrm{mg} / \mathrm{L}$ melatonin. (b) Photoperiod $+0.5 \mathrm{mg} / \mathrm{L}$ melatonin (c) Continuous light $+1.0 \mathrm{mg} / \mathrm{L}$ melatonin . 


\subsection{Interactive Effect of Light and Melatonin on Accumulation of Secondary Metabolites}

Plants have indigenous defense mechanism comprising large array of molecules that help them to survive and grow in response to a variety of environmental conditions including biotic and abiotic stresses. The major constituents of these phytochemicals are phenolics and flavonoids, which are released in unfavorable conditions [42,43]. In this study, the influence of melatonin and different light regimes on biosynthesis of these metabolites was also investigated. Callus cultures supplemented with various concentrations of melatonin were grown in three different light regimes. The highest total phenolic and flavonoid contents (TPC and TFC, respectively) were documented in callus cultures grown under continuous white light for all melatonin concentrations as compared to the rest of light regimes. Among all the treatments, $1.0 \mathrm{mg} / \mathrm{L}$ of melatonin showed highest TPC $(11.522 \mathrm{mg} / \mathrm{g})$ and TFC $(3.149 \mathrm{mg} / \mathrm{g})$ under continuous light, followed by TPC $(11.3 \mathrm{mg} / \mathrm{g})$ and TFC $(2.49 \mathrm{mg} / \mathrm{g})$ at $0.5 \mathrm{mg} / \mathrm{L}$ melatonin concentration (Figures $2 \mathrm{a}$ and $3 \mathrm{a}$ ). As for the dark treated cultures, the inverse relation of melatonin concentration and secondary metabolites production was observed i.e., metabolites accumulation was retarded with increase in melatonin concentration. Total phenolic and flavonoid productions (TPP and TFP, respectively) were also estimated by multiplying the TPC and TFC values of the cultures with their respective dry weights. Similar trend of highest TPP $(183.84 \mathrm{mg} / \mathrm{L})$ and TFP $(50.25 \mathrm{mg} / \mathrm{L})$ was recorded in cultures grown under continuous light with $1.0 \mathrm{mg} / \mathrm{L}$ melatonin (Figures $2 \mathrm{~b}$ and $\mathrm{3b}$ ). A positive correlation in biomass production and metabolites accumulation was observed in this study. Melatonin plays a contributing role in defense initiation in plants under stress conditions by regulating gene expression machinery which favors biosynthesis of specialized metabolites [44], whereas, light is regarded as an effective abiotic stress inducer in plants [45,46]. An optimal level of melatonin in response to light stress could be the only reason behind enhanced metabolites accumulation in callus culture of S. marianum. The interrelating effect of melatonin and light has recently been studied by Khan et al. [40] in callus cultures of $F$. indica, revealing a maximum production of secondary metabolites at moderate melatonin concentration $(10 \mu \mathrm{M})$ under continuous light. Similarly, Adil et al. [41] also concluded the synergistic effect of melatonin and light on enhanced synthesis of bioactive ingredients in W. somnifera adventitious roots culture. The influence of light on in vitro derived cultures has previously been studied in several other plant species with respect to their phytochemical production $[47,48]$.
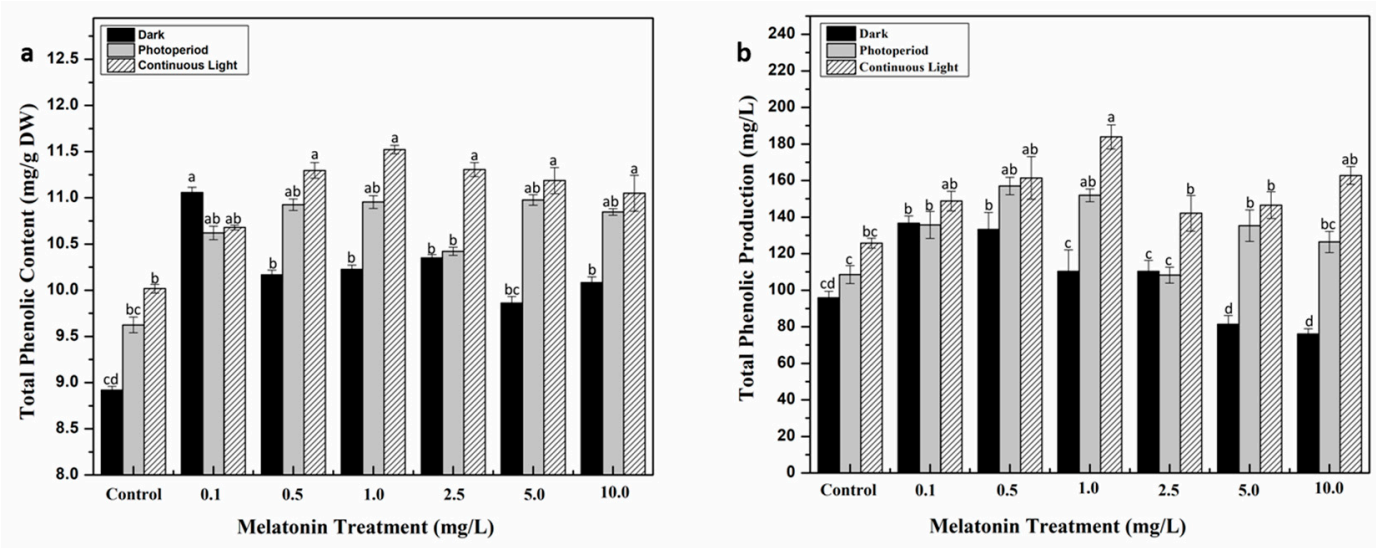

Figure 2. Phenolic accumulation in response to different melatonin and lights treatments. (a) Total phenolic content. (b) Total phenolic production. Values are means \pm SD from three replicates. Columns with similar alphabets are not significantly different $(p<0.05)$. 

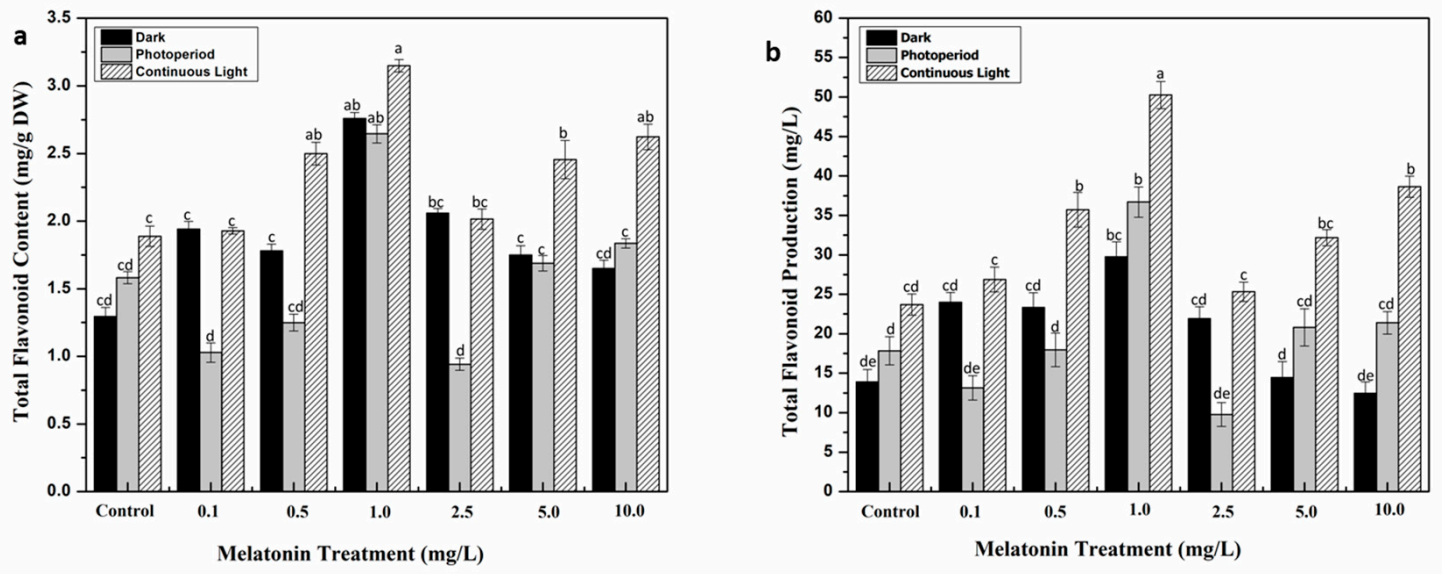

Figure 3. Flavonoids accumulation in response to different melatonin and lights treatments. (a) Total flavonoid content. (b) Total flavonoid production. Values are means \pm SD from three replicates. Columns with similar alphabets are not significantly different $(p<0.05)$.

\subsection{Effect of Light and Melatonin on Antioxidant Activities}

Environmental stress on plants causes sudden shifts in their metabolic pathways which results in the production of reactive oxygen species that could damage plant cells, membrane lipids, proteins and DNA [49-51]. In response to oxidative stress, plants produce variety of metabolic compounds including phenolics, terpenoids and flavonoids that act as protecting mechanism [52-54]. Here, the antioxidant potential of $S$. marianum calli in response to different melatonin treatments and light regimes was also explored by employing three distinct antioxidant assays i.e., ABTS (2,2-azinobis-3-ethylbenzthiazoline-6-sulphonic acid) assay (hydrogen atom transfer (HAT)-based antioxidant assay), FRAP (ferric reducing antioxidant power) assay (electron transfer (ET)-based antioxidant activity) and DPPH (2,2-diphenyl-1-picrylhydrazyl) assay (mixt HAT- and ET-based antioxidant assay). Because of its mixed HAT- and ET-based antioxidant mechanism, DPPH quenching free radical activity was indicated as percentage (\%) of free radical scavenging activity, whereas the ABTS and FRAP activities were demonstrated as TEAC (trolox $C$ equivalent antioxidant capacity, $\mu \mathrm{M}$ ). Highest DPPH activity (94.6\%) was noted for cultures grown under continuous light with $1.0 \mathrm{mg} / \mathrm{L}$ melatonin, as compared to non-melatonin control (86.33\%). Under dark conditions, $0.5 \mathrm{mg} / \mathrm{L}$ melatonin showed optimum scavenging activity (91.5\%) (Figure 4). A similar trend was noted for FRAP and ABTS assays in which $1.0 \mathrm{mg} / \mathrm{L}$ melatonin treated cultures exhibited maximum FRAP $(422.17 \mu \mathrm{M})$ and ABTS $(771.48 \mu \mathrm{M})$ activities under continuous light, whereas, in the dark conditions, $0.5 \mathrm{mg} / \mathrm{L}$ melatonin resulted in optimum FRAP $(321 \mu \mathrm{M})$ and ABTS $(545.67 \mu \mathrm{M})$ activities (Figures 5 and 6). Results of antioxidant activities revealed an obvious correlation with plant secondary metabolites. The synergistic role of continuous light and melatonin significantly increased phytochemical accumulation in callus cultures of $S$. marianum which subsequently enhanced its antioxidant potential. The highest antioxidant activity could be due to an increase in silymarin. Several studies have highlighted the potential role of silymarin in decreased production of reactive oxygen species by scavenging free radicals [55-57]. Similar findings showing the correlation of phenolic profiling with antioxidant potential have been reported in a wide variety of other plant species [58,59]. 


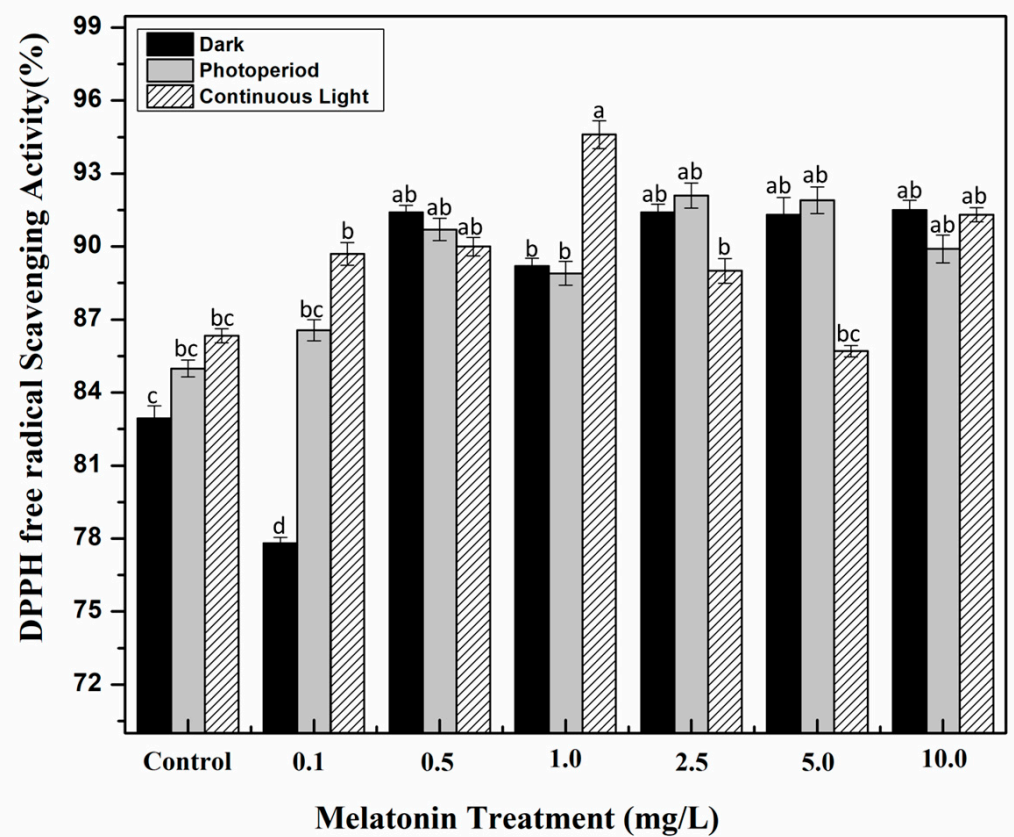

Figure 4. In vitro DPPH (2,2-diphenyl-1-picrylhydrazyl) antioxidant activity of S. marianum calli grown under different light regimes and melatonin treatments. Values are means \pm SD from three replicates. Columns with similar alphabets are not significantly different $(p<0.05)$.

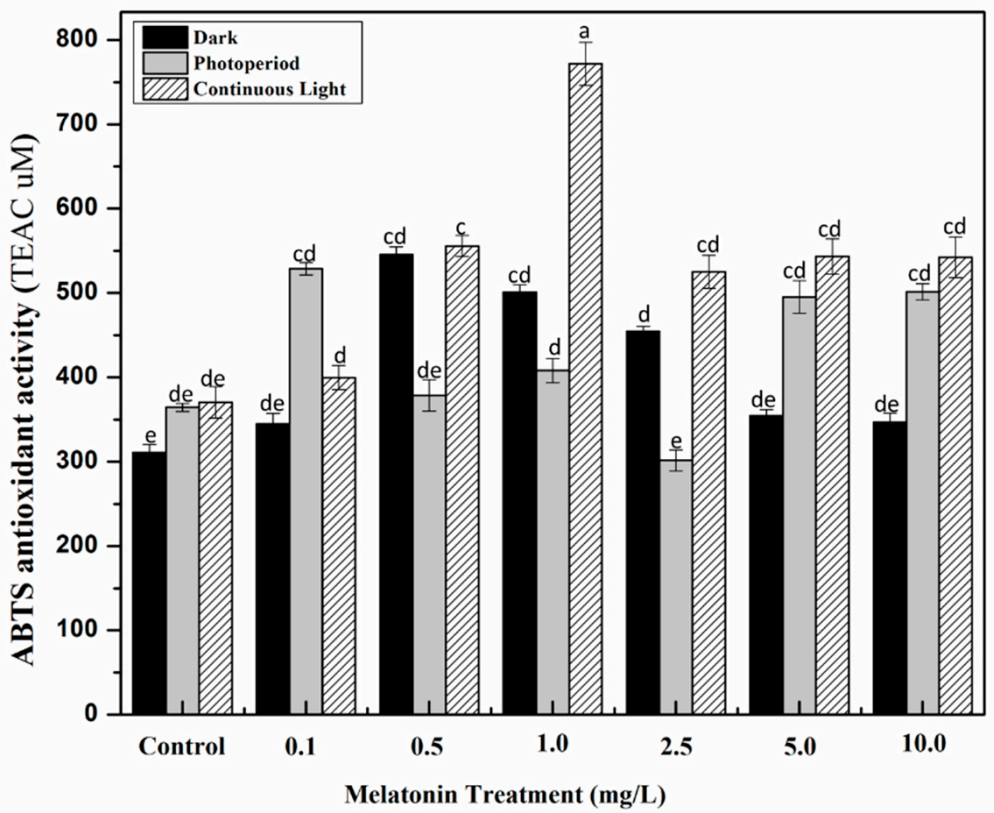

Figure 5. In vitro ABTS (2,2-azinobis-3-ethylbenzthiazoline-6-sulphonic acid) antioxidant activity of S. marianum calli grown under different light regimes and melatonin treatments. Values are means \pm SD from three replicates. Columns with similar alphabets are not significantly different $(p<0.05)$. 


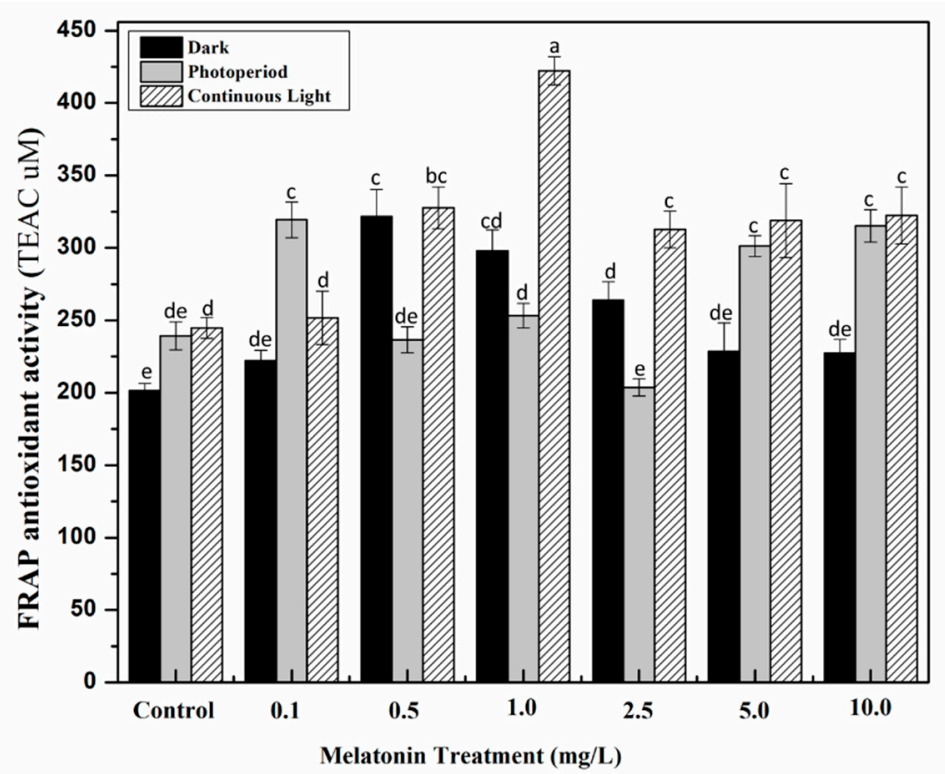

Figure 6. In vitro FRAP (ferric reducing antioxidant power) antioxidant activity of S. marianum calli grown under different light regimes and melatonin treatments. Values are means \pm SD from three replicates. Columns with similar alphabets are not significantly different $(p<0.05)$.

\subsection{Effect of Light and Melatonin on Anti-Inflammatory Potential of S. Marianum Callus Cultures}

Inflammation is immune system's response to pathogens, harmful stimuli, irritants and damaged cells. The in vitro and in vivo anti-inflammatory activities have been reported for several flavonoids. These flavonoids exert in vivo anti-inflammatory action through variety of mechanisms such as inhibition of cyclooxygenases with sometime a differential action on COX-1 vs. COX-2, phospholipase $\mathrm{A} 2$ and lipoxygenases (eicosanoid generating enzymes), thereby decreasing leukotrienes and prostanoid concentrations [60]. Different in vitro assays like COX-1, COX-2, 15-LOX and sPLA2 were here carried out to verify the anti-inflammatory potential of $S$. marianum callus cultures. Of all the treatments, continuous light with $1.0 \mathrm{mg} / \mathrm{L}$ melatonin gave most effective results towards the inhibitory actions of all assays performed. Highest inhibitory activity was shown against 15-LOX (42.33 $\pm 1.59 \%)$ followed by COX-1 (37.15 $\pm 1.29 \%)$, sPLA2 (35.70 $\pm 0.99 \%)$ and COX-2 (29.03 $\pm 0.97 \%)$, respectively in cultures grown under continuous light with $1.0 \mathrm{mg} / \mathrm{L}$ melatonin. Percent (\%) inhibitions of different samples have been depicted in Table 2. Dark grown cultures showed maximum anti-inflammatory activity at $0.5 \mathrm{mg} / \mathrm{L}$ melatonin, whereas, cultures placed under continuous light displayed optimum results at $1.0 \mathrm{mg} / \mathrm{L}$ melatonin concentration. It has previously been established by many studies that silymarin contents are responsible for enhanced anti-inflammatory effect in S. marianum [61-63]. Pradhan et al. [64] also concluded that increased production of silymarin content significantly enhanced the anti-inflammatory activity. Phytochemicals in plants are solely responsible for enzymatic inhibition that causes inflammation in the body $[19,65,66]$.

Table 2. Anti-inflammatory potential of S. marianum callus cultures grown under different light regimes and melatonin treatments.

\begin{tabular}{|c|c|c|c|c|c|}
\hline Light Regime & Melatonin (mg/L) & 15-LOX (\% Inh) & COX-1 (\% Inh) & sPLA $_{2}$ (\% Inh) & COX-2 (\% Inh) \\
\hline \multirow{7}{*}{ Dark } & Control & $18.56 \pm 1.05^{c}$ & $20.55 \pm 1.08^{\mathrm{cd}}$ & $19.83 \pm 1.45 \mathrm{bc}$ & $13.37 \pm 1.34 \mathbf{b c}$ \\
\hline & 0.1 & $20.90 \pm 1.43^{c}$ & $21.20 \pm 1.30 \mathrm{~cd}$ & $22.27 \pm 0.95$ bc & $15.93 \pm 2.01 b c$ \\
\hline & 0.5 & $30.99 \pm 0.99 b$ & $28.60 \pm 1.54^{b}$ & $28.96 \pm 1.03 a b$ & $22.24 \pm 1.34 \mathrm{ab}$ \\
\hline & 1.0 & $28.74 \pm 2.56^{\mathbf{b}}$ & $26.94 \pm 0.83 \mathbf{b c}$ & $27.37 \pm 1.30^{\mathrm{ab}}$ & $20.78 \pm 0.94^{b}$ \\
\hline & 2.5 & $26.41 \pm 1.98$ bc & $25.51 \pm 1.54$ bc & $25.08 \pm 1.28^{\mathbf{b}}$ & $19.05 \pm 1.56^{\mathbf{b}}$ \\
\hline & 5.0 & $21.38 \pm 2.03^{c}$ & $21.47 \pm 1.48^{\mathrm{cd}}$ & $22.70 \pm 1.84$ bc & $16.25 \pm 2.01 b c$ \\
\hline & 10.0 & $20.99 \pm 3.51^{c}$ & $21.07 \pm 1.56^{\mathrm{cd}}$ & $22.62 \pm 1.26 \mathrm{bc}$ & $16.05 \pm 1.67 \mathrm{bc}$ \\
\hline
\end{tabular}


Table 2. Cont.

\begin{tabular}{|c|c|c|c|c|c|}
\hline Light Regime & Melatonin (mg/L) & 15-LOX (\% Inh) & COX-1 (\% Inh) & $\mathrm{sPLA}_{2}(\%$ Inh) & COX-2 (\% Inh) \\
\hline \multirow{7}{*}{ Photoperiod } & Control & $21.87 \pm 2.50^{c}$ & $21.62 \pm 1.62 \mathrm{~cd}$ & $23.42 \pm 1.49 b c$ & $16.68 \pm 0.93 \mathbf{b c}$ \\
\hline & 0.1 & $30.13 \pm 1.87^{b}$ & $27.90 \pm 1.38^{b}$ & $28.80 \pm 0.84 \mathrm{ab}$ & $21.89 \pm 1.45^{\mathrm{ab}}$ \\
\hline & 0.5 & $22.59 \pm 1.14$ bc & $22.48 \pm 2.05^{\mathrm{c}}$ & $23.23 \pm 2.03^{b}$ & $16.92 \pm 1.04$ bc \\
\hline & 1.0 & $24.07 \pm 1.41$ bc & $23.47 \pm 1.56^{\mathrm{c}}$ & $24.35 \pm 1.82 \mathbf{b}$ & $17.88 \pm 0.72$ bc \\
\hline & 2.5 & $18.72 \pm 1.78^{c}$ & $19.51 \pm 0.83 \mathrm{~cd}$ & $21.02 \pm 0.59$ bc & $14.63 \pm 1.94$ bc \\
\hline & 5.0 & $28.45 \pm 1.05^{b}$ & $26.64 \pm 1.55 \mathrm{bc}$ & $27.58 \pm 1.47 \mathrm{ab}$ & $20.77 \pm 2.04^{b}$ \\
\hline & 10.0 & $26.36 \pm 1.32$ bc & $24.66 \pm 1.83^{c}$ & $22.98 \pm 2.44 \mathrm{bc}$ & $18.66 \pm 1.43^{b}$ \\
\hline \multirow{7}{*}{$\begin{array}{c}\text { Continuous } \\
\text { Light }\end{array}$} & Control & $28.37 \pm 1.69 b$ & $22.66 \pm 0.80^{c}$ & $21.79 \pm 1.28$ bc & $16.23 \pm 1.93 \mathrm{bc}$ \\
\hline & 0.1 & $23.65 \pm 0.97 \mathrm{bc}$ & $23.09 \pm 0.92 \mathrm{c}$ & $24.25 \pm 1.66^{\mathbf{b}}$ & $17.68 \pm 1.03$ bc \\
\hline & 0.5 & $31.49 \pm 1.23^{\mathbf{b}}$ & $28.97 \pm 1.56^{\mathbf{b}}$ & $29.35 \pm 1.22 \mathrm{ab}$ & $22.59 \pm 1.05 \mathrm{ab}$ \\
\hline & 1.0 & $42.33 \pm 1.59^{a}$ & $37.15 \pm 1.29 \mathrm{a}$ & $35.70 \pm 0.99^{a}$ & $29.03 \pm 0.97^{a}$ \\
\hline & 2.5 & $29.95 \pm 1.86^{\mathbf{b}}$ & $27.80 \pm 1.45^{\mathbf{b}}$ & $28.35 \pm 2.76^{a b}$ & $21.62 \pm 1.46^{\mathrm{ab}}$ \\
\hline & 5.0 & $30.87 \pm 1.23^{\mathbf{b}}$ & $28.52 \pm 1.33^{b}$ & $28.76 \pm 1.55^{a b}$ & $22.11 \pm 1.35^{\mathrm{ab}}$ \\
\hline & 10.0 & $30.82 \pm 1.50^{\mathbf{b}}$ & $28.45 \pm 1.20^{b}$ & $29.00 \pm 1.39 \mathrm{ab}$ & $22.20 \pm 1.04$ ab \\
\hline
\end{tabular}

15-LOX: Arachidonate 15-Lipoxygenase; $\mathrm{sPLA}_{2}$ : phospholipase A2; COX: cyclooxygenase. Values are means \pm SD from three replicates. Columns with similar alphabets are not significantly different $(p<0.05)$. (\% inh = percent inhibition). The highest inhibition percentages are in bold.

\subsection{Effect of Light and Melatonin on Silymarin}

The individual composition of silymarin was also quantified in the current study against various melatonin concentrations and light regimes. Continuous light showed a prominent effect on total silymarin content (TSC) as compared to the rest of light regimes, whereas melatonin produced variable results in response to light treatment. Under continuous light, optimal TSC (11.92 mg/g DW) was noted in $1.0 \mathrm{mg} / \mathrm{L}$ melatonin treated cultures compared to control $(7.189 \mathrm{mg} / \mathrm{g}$ DW). Similarly, maximum TSC $(9.08 \mathrm{mg} / \mathrm{g} \mathrm{DW})$ was found in cultures grown in the dark with $0.5 \mathrm{mg} / \mathrm{L}$ melatonin. Cultures grown under photoperiod displayed highest TSC $(9.01 \mathrm{mg} / \mathrm{g} \mathrm{DW})$ at $0.1 \mathrm{mg} / \mathrm{L}$ melatonin concentration (Figure 7). Results suggested that lower concentrations of melatonin favor optimum secondary metabolites biosynthesis by overcoming stress induced by continuous light and dark treatments. Our results are in harmony with those shown by Fazal et al. [39] who concluded that low exogenously applied melatonin concentration produced higher biomass accumulation and enzymatic activity in P. vulgaris cultures grown in vitro. Similarly, Adil at al. [41] also showed maximum secondary metabolites accumulation in melatonin treated cultures in continuous light as compared to dark and photoperiod regimes. High-performance liquid chromatography (HPLC) analysis of individual compounds showed that silybin A, silychristin and silybin B are the major compounds synthesized in callus cultures of Milk thistle, as previously reported in various studies $[67,68]$. Melatonin $(1.0 \mathrm{mg} / \mathrm{L})$ showed maximum accumulation of silybin A $(1.45 \mathrm{mg} / \mathrm{g} \mathrm{DW})$, silychristin $(1.08 \mathrm{mg} / \mathrm{g} \mathrm{DW})$ and silybin B (7.43 mg/g DW) under continuous light as compared to other treatments (Table 3). Silybin (A and B) are considered as primary compounds in Milk thistle extract as previously reported [67,69], which is in accordance with our study. Continuous light has a profound effect on biological synthesis of precious secondary metabolites. Previous studies on O. basilicum also revealed highest phytochemical accumulation grown under white light $[70,71]$. Taxifolin accumulation was also determined under different light regimes and melatonin concentrations. As compared to control (51.7 $\mu \mathrm{g} / \mathrm{g} \mathrm{DW})$, maximum taxifolin $(136 \mu \mathrm{g} / \mathrm{g}$ DW) was recorded for $1.0 \mathrm{mg} / \mathrm{L}$ melatonin treated cultures grown under continuous light. Younas et al. [72] also reported maximum taxifolin accumulation in S. marianum calli grown under continuous white light. Since silymarin contents are usually synthesized and derived from taxifolin in S. marianum, it is safe to assume that low level of taxifolin could be due to its conversion into silymarin contents [73,74]. 
Table 3. Quantification of silymarin compounds in callus cultures of S. marianum grown under different light regimes and melatonin treatments.

\begin{tabular}{|c|c|c|c|c|c|c|c|c|c|}
\hline \multirow[t]{2}{*}{ Light Regimes } & \multirow[t]{2}{*}{ Melatonin $(\mathrm{mg} / \mathrm{L})$} & \multicolumn{8}{|c|}{ Silymarin Compounds (mg/g DW) } \\
\hline & & Silybin A & Silybin B & Isosilybin A & Isosilybin B & Silychristin & Isosilychristin & Silydianin & Taxifolin \\
\hline \multirow{7}{*}{ Dark } & Control & $0.62 \pm 0.05^{\mathrm{cd}}$ & $3.34 \pm 0.04 \mathrm{e}$ & $0.17 \pm 0.002^{\mathbf{b}}$ & $0.15 \pm 0.03 \mathbf{b c}$ & $0.58 \pm 0.06^{c}$ & $0.28 \pm 0.02$ bc & $0.60 \pm 0.08$ bc & $0.05 \pm 0.009 \mathbf{b}$ \\
\hline & 0.1 & $0.67 \pm 0.002 \mathrm{~cd}$ & $3.67 \pm 0.06$ de & $0.19 \pm 0.04 \mathrm{ab}$ & $0.15 \pm 0.02 \mathbf{b c}$ & $0.60 \pm 0.03^{c}$ & $0.29 \pm 0.09 \mathbf{b c}$ & $0.61 \pm 0.064^{\mathbf{b}}$ & $0.06 \pm 0.005^{b}$ \\
\hline & 0.5 & $1.06 \pm 0.045^{\mathbf{b}}$ & $5.59 \pm 0.076 \mathbf{b c}$ & $0.22 \pm 0.055^{a}$ & $0.22 \pm 0.054 \mathrm{ab}$ & $0.82 \pm 0.028^{\mathbf{b}}$ & $0.38 \pm 0.059 \mathrm{ab}$ & $0.68 \pm 0.055 \mathrm{ab}$ & $0.13 \pm 0.003 \mathbf{a}$ \\
\hline & 1.0 & $0.97 \pm 0.037 \mathbf{b c}$ & $5.13 \pm 0.056^{c}$ & $0.21 \pm 0.029 \mathrm{ab}$ & $0.21 \pm 0.053^{\mathbf{b}}$ & $0.77 \pm 0.048$ bc & $0.36 \pm 0.040^{\mathbf{b}}$ & $0.66 \pm 0.087^{\mathbf{b}}$ & $0.08 \pm 0.006^{a b}$ \\
\hline & 2.5 & $0.82 \pm 0.039 c$ & $4.37 \pm 0.042 \mathrm{~d}$ & $0.21 \pm 0.019 \mathbf{a b}$ & $0.19 \pm 0.048^{\mathbf{b}}$ & $0.73 \pm 0.098$ bc & $0.33 \pm 0.076 \mathbf{a b}$ & $0.67 \pm 0.067 \mathbf{a b}$ & $0.08 \pm 0.004 \mathrm{ab}$ \\
\hline & 5.0 & $0.70 \pm 0.048^{\mathrm{cd}}$ & $3.81 \pm 0.039 \mathrm{de}$ & $0.19 \pm 0.074 \mathrm{ab}$ & $0.16 \pm 0.047 \mathrm{bc}$ & $0.60 \pm 0.038^{c}$ & $0.29 \pm 0.033 \mathbf{b c}$ & $0.61 \pm 0.062 \mathbf{b}$ & $0.06 \pm 0.007^{b}$ \\
\hline & 10.0 & $0.69 \pm 0.044^{\mathrm{cd}}$ & $3.82 \pm 0.027 \mathrm{de}$ & $0.19 \pm 0.06^{\mathrm{ab}}$ & $0.15 \pm 0.051 \mathbf{b c}$ & $0.59 \pm 0.064^{c}$ & $0.29 \pm 0.009$ bc & $0.60 \pm 0.094 \mathbf{b c}$ & $0.06 \pm 0.008^{\mathbf{b}}$ \\
\hline \multirow{7}{*}{ Photoperiod } & Control & $0.74 \pm 0.04^{\mathrm{c}}$ & $4.08 \pm 0.03^{\mathrm{d}}$ & $0.19 \pm 0.05^{\mathrm{ab}}$ & $0.16 \pm 0.02$ bc & $0.60 \pm 0.07^{c}$ & $0.30 \pm 0.04$ bc & $0.59 \pm 0.09$ bc & $0.06 \pm 0.004^{\mathbf{b}}$ \\
\hline & 0.1 & $1.05 \pm 0.09 \mathbf{b}$ & $5.59 \pm 0.89$ bc & $0.21 \pm 0.04 \mathbf{a b}$ & $0.21 \pm 0.04 \mathbf{b}$ & $0.79 \pm 0.05 \mathbf{b}$ & $0.37 \pm 0.06 \mathrm{ab}$ & $0.66 \pm 0.01 \mathbf{b}$ & $0.09 \pm 0.002 \mathrm{ab}$ \\
\hline & 0.5 & $0.72 \pm 0.06^{\mathrm{c}}$ & $3.93 \pm 0.74 \mathrm{de}$ & $0.21 \pm 0.05$ ab & $0.16 \pm 0.06 \mathbf{b c}$ & $0.64 \pm 0.09^{c}$ & $0.30 \pm 0.08$ bc & $0.63 \pm 0.05^{\mathbf{b}}$ & $0.06 \pm 0.008^{b}$ \\
\hline & 1.0 & $0.79 \pm 0.048^{c}$ & $4.27 \pm 0.55^{\mathrm{d}}$ & $0.20 \pm 0.07 \mathbf{a b}$ & $0.17 \pm 0.08 \mathbf{b c}$ & $0.66 \pm 0.03^{c}$ & $0.31 \pm 0.07^{\mathbf{b}}$ & $0.63 \pm 0.03^{\mathbf{b}}$ & $0.07 \pm 0.006^{\mathbf{b}}$ \\
\hline & 2.5 & $0.60 \pm 0.07 \mathrm{~cd}$ & $3.34 \pm 0.48 \mathrm{e}$ & $0.18 \pm 0.095 \mathbf{b}$ & $0.14 \pm 0.03 \mathbf{b c}$ & $0.54 \pm 0.02 \mathrm{~cd}$ & $0.27 \pm 0.03 \mathbf{b c}$ & $0.59 \pm 0.08$ bc & $0.05 \pm 0.005^{b}$ \\
\hline & 5.0 & $0.98 \pm 0.039 \mathbf{b c}$ & $5.23 \pm 0.95^{c}$ & $0.19 \pm 0.004 \mathrm{ab}$ & $0.20 \pm 0.05^{\mathbf{b}}$ & $0.75 \pm 0.06^{b c}$ & $0.36 \pm 0.05^{\mathbf{b}}$ & $0.65 \pm 0.09 \mathbf{b}$ & $0.08 \pm 0.007 \mathrm{ab}$ \\
\hline & 10.0 & $0.81 \pm 0.055^{c}$ & $4.34 \pm 0.33^{\mathrm{d}}$ & $0.20 \pm 0.056 \mathrm{ab}$ & $0.18 \pm 0.07^{\mathbf{b}}$ & $0.67 \pm 0.04^{\mathrm{c}}$ & $0.32 \pm 0.01 \mathbf{b}$ & $0.63 \pm 0.05^{\mathbf{b}}$ & $0.07 \pm 0.003 \mathbf{b}$ \\
\hline \multirow{7}{*}{$\begin{array}{c}\text { Continuous } \\
\text { Light }\end{array}$} & Control & $0.80 \pm 0.05^{c}$ & $4.32 \pm 0.98^{\mathrm{d}}$ & $0.20 \pm 0.03^{\mathrm{ab}}$ & $0.17 \pm 0.01 \mathbf{b c}$ & $0.66 \pm 0.02^{c}$ & $0.31 \pm 0.07^{\mathbf{b}}$ & $0.63 \pm 0.04^{\mathbf{b}}$ & $0.051 \pm 0.005^{b}$ \\
\hline & 0.1 & $0.79 \pm 0.03^{c}$ & $4.27 \pm 0.07 \mathrm{~d}$ & $0.20 \pm 0.044^{a b}$ & $0.17 \pm 0.03 \mathbf{b c}$ & $0.65 \pm 0.06^{c}$ & $0.31 \pm 0.09 \mathbf{b}$ & $0.62 \pm 0.08^{\mathbf{b}}$ & $0.07 \pm 0.007^{\mathbf{b}}$ \\
\hline & 0.5 & $1.08 \pm 0.07^{\mathbf{b}}$ & $5.71 \pm 0.05 \mathrm{bc}$ & $0.22 \pm 0.096^{a}$ & $0.22 \pm 0.07^{\mathbf{b}}$ & $0.83 \pm 0.05^{\mathbf{b}}$ & $0.38 \pm 0.03^{\mathrm{ab}}$ & $0.68 \pm 0.06^{\mathrm{ab}}$ & $0.09 \pm 0.009 \mathrm{ab}$ \\
\hline & 1.0 & $1.45 \pm 0.05^{\mathrm{a}}$ & $7.43 \pm 0.06^{a}$ & $0.24 \pm 0.055^{a}$ & $0.30 \pm 0.05^{a}$ & $1.08 \pm 0.08^{a}$ & $0.47 \pm 0.04^{a}$ & $0.77 \pm 0.01^{b}$ & $0.13 \pm 0.005^{a}$ \\
\hline & 2.5 & $1.03 \pm 0.08^{\mathbf{b}}$ & $5.42 \pm 0.04^{c}$ & $0.21 \pm 0.039 \mathrm{ab}$ & $0.21 \pm 0.08^{\mathbf{b}}$ & $0.79 \pm 0.03^{b}$ & $0.37 \pm 0.06^{\mathrm{ab}}$ & $0.66 \pm 0.05^{\mathbf{b}}$ & $0.09 \pm 0.008$ ab \\
\hline & 5.0 & $1.05 \pm 0.06^{\mathbf{b}}$ & $5.52 \pm 0.098^{c}$ & $0.22 \pm 0.084^{\mathbf{a}}$ & $0.22 \pm 0.04 \mathbf{b}$ & $0.82 \pm 0.09 b$ & $0.37 \pm 0.032 \mathbf{a b}$ & $0.68 \pm 0.03 \mathrm{ab}$ & $0.09 \pm 0.004 \mathrm{ab}$ \\
\hline & 10.0 & $1.06 \pm 0.04^{\mathbf{b}}$ & $5.62 \pm 0.05 \mathrm{bc}$ & $0.22 \pm 0.044^{\mathbf{a}}$ & $0.22 \pm 0.02 \mathbf{b}$ & $0.81 \pm 0.04 \mathbf{b}$ & $0.38 \pm 0.085 \mathrm{ab}$ & $0.67 \pm 0.07 \mathrm{ab}$ & $0.08 \pm 0.003 \mathrm{ab}$ \\
\hline
\end{tabular}

Values are means \pm SD from three replicates. Columns with similar alphabets are not significantly different $(p<0.05)$. (Optimum values are highlighted bold). 


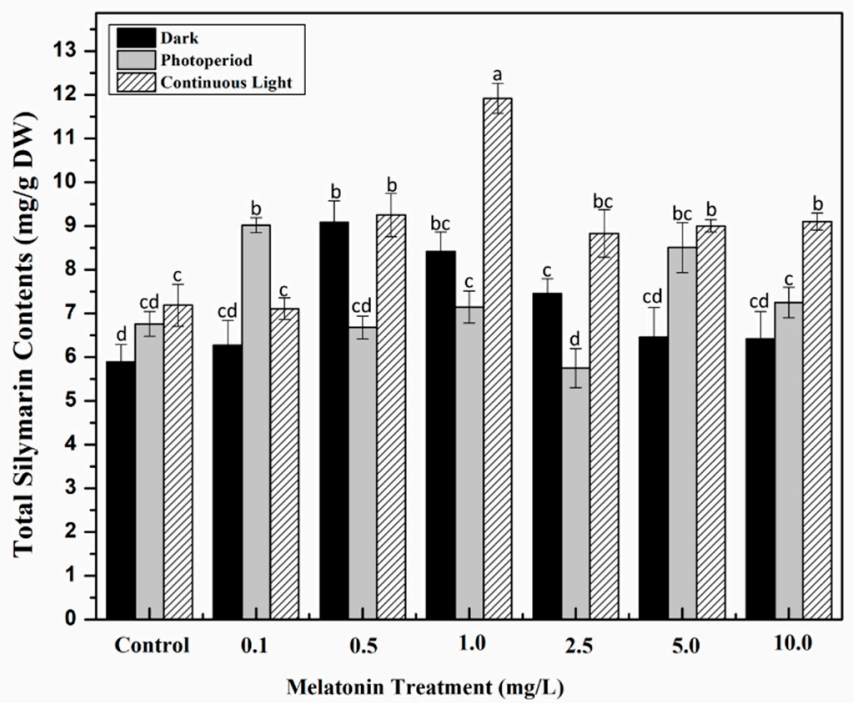

Figure 7. Total silymarin contents in callus cultures of S. marianum grown under different light regimes and melatonin treatments. Values are means \pm SD from three replicates. Columns with similar alphabets are not significantly different $(p<0.05)$.

\section{Materials and Methods}

\subsection{Chemicals}

All the chemicals used in the present study were of analytical grade quality and purchased from Thermo (Illkirch, France). The deionized water was produced using a milli-Q water purification system (Merck Millipore, Molsheim, France). Prior to their use for analysis, all solutions were filtered through $0.45 \mu \mathrm{m}$ nylon syringe membranes (Merck Millipore, Molsheim, France). All phytohormones and commercial standards were purchased from Sigma-Aldrich (Saint-Quentin Fallavier, France).

\subsection{Seed Germination and Explant Collection}

The seeds of Silybum marianum were taken from the seed bank of the Plant Cell Culture Lab (PCCL), Department of Biotechnology, Quaid-i-Azam University, Pakistan. Seeds were thoroughly washed and then subjected to surface sterilization. Mercuric chloride solution $(0.1 \%)$ was used for $40 \mathrm{~s}$, followed by ethanol washing $(70 \%)$ for 90 seconds. Seeds were then washed again three times with autoclaved distilled water to free them from any unwanted particles. Surface sterilized seeds were then inoculated on Murashige and Skoog (MS) media (Murashige and Skoog 1962) [75] supplemented with agar $(0.8 \%)$ and sucrose $(3 \%)$ and placed in growth room with $25 \pm 2{ }^{\circ} \mathrm{C}$ temperature and $16 / 8 \mathrm{~h}$ light/dark cycle (photoperiod). The media $\mathrm{pH}$ was maintained at 5.6-5.7, prior to being autoclaved at $121{ }^{\circ} \mathrm{C}$ for $20 \mathrm{~min}$. Plantlets (4 weeks old) were then employed as a source of explant collection for callus induction.

\subsection{Callus Culture Establishment}

Leaf explants $\left(0.5 \mathrm{~cm}^{2}\right)$ were excised from in vitro germinated plantlets (4 weeks old) and placed on MS media containing different hormonal concentrations $(0.5-10 \mathrm{mg} / \mathrm{L})$ of thidiazuron (TDZ), 6-benzyl aminopurine (BAP) and $\alpha$-naphthalene acetic acid (NAA), either alone or in conjunction with $1.0 \mathrm{mg} / \mathrm{L}$ NAA along with agar $(0.8 \%)$ and sucrose $(3 \%)$ for callus culture establishment. Callus culture was established under controlled environmental conditions in growth chamber. Four weeks old calli were then sub-cultured on respective hormonal media for maximum biomass production. 


\subsection{Melatonin and Light Treatment}

Preliminary results of callus culture optimization on different hormones showed optimum response on combined treatment of $0.5 \mathrm{mg} / \mathrm{L} \mathrm{BAP}$ and $1.0 \mathrm{mg} / \mathrm{L} \mathrm{NAA} \mathrm{(unpublished} \mathrm{data),} \mathrm{as} \mathrm{compared}$ to the rest of treatments. Four weeks old sub-cultured calli $(1.0 \mathrm{~g})$ at optimized hormonal concentration $(0.5 \mathrm{mg} / \mathrm{L} \mathrm{BAP}+1.0 \mathrm{mg} / \mathrm{L} \mathrm{NAA})$ was then used to inoculate with various concentrations $(0.1,0.5$, $1.0,2.5,5.0,10 \mathrm{mg} / \mathrm{L}$ ) of melatonin on the same optimum hormonal media. Callus without melatonin treatment was used as control. The whole experiment was treated with three different light regimes: dark ( $24 \mathrm{~h})$, photoperiod (16/8 h light/dark) and continuous white light $(24 \mathrm{~h})$ at $25 \pm 2{ }^{\circ} \mathrm{C}$ to check the interlinking effect of light and melatonin. Experiment was conducted in triplicate and harvested after 28 days for estimation of fresh weight (FW), dry weight (DW) and phytochemical contents.

\subsection{Total Flavonoid and Phenolic Contents}

To investigate the accumulation of phytochemicals, extraction was carried out from dried samples according to Zahir et al. [56] with modifications. Dried powder (100 mg) from each sample was mixed with $99.9 \%$ methanol $(500 \mu \mathrm{L}$ ) and vortexed for approximately $5 \mathrm{~min}$, followed by sonication at room temperature for $30 \mathrm{~min}$. Centrifugation of the reaction mixture was undertaken for $10 \mathrm{~min}$ at 15,000 rpm and the resultant supernatant was separately kept at $4{ }^{\circ} \mathrm{C}$ for phytochemical assays. Total phenolic content (TPC) was estimated with the help of a Folin-Ciocalteu (FC) reagent using slightly modified method of Singleton and Rossi (1965) [76]. Reaction mixture was prepared using methanol extracted sample $(20 \mu \mathrm{L}), \mathrm{FC}$ reagent $(90 \mu \mathrm{L})$ and $\mathrm{NA}_{2} \mathrm{CO}_{3}(90 \mu \mathrm{L})$. Gallic acid was employed as a standard and the TPC was expressed as gallic acid equivalents (GAE)/g of DW. Using microplate reader (BioTek ELX800 Absorbance Microplate Reader, BioTek Instruments, Colmar, France), the absorbance was taken at $630 \mathrm{~nm}$. Similarly, total flavonoid content (TFC) was also measured using previously described aluminum chloride colorimetric method [77] with slight changes. Reaction mixture was prepared using the sample $(20 \mu \mathrm{L})$, aluminum chloride $(10 \mu \mathrm{L})$, distilled water $(160 \mu \mathrm{L})$ and potassium acetate $(10 \mu \mathrm{L})$ to make $200 \mu \mathrm{L}$ of final volume. The standard used in this assay was quercetin and the TFC was expressed as quercetin equivalents $(\mathrm{QE}) / \mathrm{g}$ of DW. Prior to noting absorbance at $415 \mathrm{~nm}$ using microplate reader (BioTek ELX800 Absorbance Microplate Reader, BioTek Instruments, Colmar, France), the reaction mixture was incubated for half an hour.

\subsection{Estimation of Antioxidant Activity}

\subsubsection{DPPH Activity (\%)}

DPPH (2,2-diphenyl-1-picrylhydrazyl) quenching free radical activity of the samples was performed using the protocol of Abbasi et al. [78]. $20 \mu \mathrm{L}$ sample was added into each well of microplate, followed by addition of DPPH reagent solution of $180 \mu \mathrm{L}$ and then incubated in the dark at room temperature for $60 \mathrm{~min}$. Ascorbic acid final concentrations $(05,10,20$ and $40 \mu \mathrm{g} / \mathrm{mL}$ ) and $180 \mu \mathrm{L}$ of DPPH with $20 \mu \mathrm{L}$ of DMSO were taken as negative control. Microplate reader (BioTek ELX800 Absorbance Microplate Reader, BioTek Instruments, Colmar, France) was used to record the solution absorbance at $517 \mathrm{~nm}$. The following formula was then employed to calculate DPPH activity:

$$
\% \text { scavenging }=100 \times(1-\mathrm{AE} / \mathrm{AD})
$$

where, $\mathrm{AE}=$ absorbance of the mixture at $517 \mathrm{~nm}$ with addition of sample, and $\mathrm{AD}=$ absorbance of $\mathrm{DPPH}$ solution without addition of anything.

\subsubsection{Ferric Reducing Antioxidant Power (FRAP) Assay}

For this assay, previous method of Benzie and Strain was followed [79]. Briefly, $190 \mu \mathrm{L}$ of FRAP solution [containing 2,4,6-Tri(2-pyridyl)-s-triazine (TPTZ; $10 \mathrm{mM}$ ); acetate buffer ( $300 \mathrm{mM})$ of pH 3.6 and $20 \mathrm{mM}$ ferric chloride hexahydrate $(\mathrm{FeCl} 3.6 \mathrm{H} 2 \mathrm{O})$; ratio 10:1:1 $(v / v / v)]$ was mixed with $10 \mu \mathrm{L}$ of 
samples. The reaction mixtures were then put for $15 \mathrm{~min}$ at room temperature. Using microplate reader (BioTek ELX800 Absorbance Microplate Reader, BioTek Instruments, Colmar, France), the absorbance was noted at $630 \mathrm{~nm}$. Tests were carried out in triplicates and the antioxidant activity was demonstrated as TEAC.

\subsubsection{Antioxidant ABTS Assay}

Procedure described by Velioglu et al. [80] was employed for the ABTS (2,2-azinobis-3ethylbenzthiazoline-6-sulphonic acid) assay. Briefly, the ABTS solution was prepared by mixing $7 \mathrm{mM}$ ABTS salt equal proportion with $2.45 \mathrm{mM}$ potassium per sulphate and the same mixture was then put in the dark for $16 \mathrm{~h}$. The solution absorbance was noted at $734 \mathrm{~nm}$ and, before mixing with extracts, it was adjusted to 0.7 . The mixture was put again in the dark for $15 \mathrm{~min}$ at room temperature $\left(25 \pm 1{ }^{\circ} \mathrm{C}\right)$ and the absorbance was then noted at $734 \mathrm{~nm}$ with the aid of a microplate reader (BioTek ELX800 Absorbance Microplate Reader, BioTek Instruments, Colmar, France). The assays were performed in triplicates and the antioxidant activity was expressed as TEAC.

\subsection{Anti-Inflammatory Activities}

\subsubsection{Inhibitory Activity Against COX-1 and COX-2}

The inhibitory activity of selected samples were checked against COX-2 and COX-1 using COX-2 (human) and COX-1 (Ovine) assay kit (701050, Cayman Chem. Co, Interchim, Montluçon, France) following the instructions of the manufacturer. The substrate at $1.1 \mathrm{mM}$ concentration was arachidonic acid and the positive control was ibuprofen $(10 \mu \mathrm{M})$. The COXs peroxidase component was measured by the kit. The Synergy II reader (BioTek Instruments, Colmar, France) was used at $590 \mathrm{~nm}$ in a 96-well microplate for 5 min to check oxidized $N, N, N^{\prime}, N^{\prime}$-tetramethyl-p-phenylenediamine.

\subsubsection{Inhibitory Activity Against 15-LOX}

To check the inhibitory activity of the samples against 15-LOX, assay kit (760700, Cayman Chem. Co., Interchim, Montluçon, France) was used following the instructions of the manufacturer. The substrate taken was arachidonic acid $(10 \mu \mathrm{M})$ while $100 \mu \mathrm{M}$ nordihydroguaiaretic acid (NDGA) was taken as positive control inhibitor. The hydroperoxides concentration produced during the lipooxygenation reaction was measured by the kit using filtered soy 15-lipooxygenase standard in $10 \mathrm{mM}$ Tris-HCl buffer at $7.4 \mathrm{pH}$. Synergy II reader (BioTek Instruments, Colmar, France) was used for measurement at $940 \mathrm{~nm}$ in a 96-well microplate. After $5 \mathrm{~min}$ incubation of the inhibitor and enzyme, the absorbance was recorded followed by incubation of $15 \mathrm{~min}$ after addition of the substrate and incubation for $5 \mathrm{~min}$ after addition of chromogen.

\subsubsection{Inhibitory Activity Against Secretory Phospholipase A2 (sPLA2)}

To test the inhibitory ability of samples against sPLA2, an assay kit (10004883, Cayman Chem. Co, Interchim, Montluçon, France) was used following instructions of the manufacturer. The substrate was diheptanoyl thio-PC $(1.44 \mathrm{mM})$ while the thiotheramide-PC $(100 \mu \mathrm{M})$ was used as a positive control inhibitor. The cleavage of diheptanoyl thio-PC ester releases free thiols which was measured by Synergy II reader (BioTek Instruments, Colmar, France) at $420 \mathrm{~nm}$ in a 96-well microplate using DTNB (5-5'-dithio-bis-(2-nitrobenzoic acid). The \% inhibition was calculated as:

$$
\% \text { Inhibition }=[(\mathrm{IA}-\text { Inhibitor }) / \mathrm{IA}] \times 100
$$

where, Inhibitor $=$ Activity of enzyme with inhibitor addition; IA $=100 \%$ activity of enzyme in the absence of inhibitor. 
3.8. High-Performance Liquid Chromatography Electrospray Ionization Mass Spectrometry (HPLC-ESI-MS) Analysis

Liquid chromatography-mass spectrometry (LC-MS) analysis was done to quantify silymarin compounds, as previously described by Drouet et al. [81] using using aWaters 2695 Alliance coupled with a single quadrupole mass spectrometer ZQ (Waters-Micromass, Manchester, UK), equipped with an electrospray ion source (ESI-MS). The examination of all samples was done three times, and the results were revealed as $\mathrm{mg} / \mathrm{g}$ sample DW. Taxofolin and flavonolignans were identified by comparison with authentic standards (Sigma Aldrich). The linear correlations between peak area and standard concentrations were found to be high in the range of $0.5-50 \mu \mathrm{g} / \mathrm{mL}$. The resulting linear equations were obtained with $\mathrm{R}^{2}$-value for a six-point calibration graph $>0.99$, with Taxifolin $(\mathrm{y}=1292.9+$ $0.7, \mathrm{R}^{2}=0.9989$, limit of detection $(\mathrm{LOD})=0.09 \mu \mathrm{g} / \mathrm{mL}$, limit of quantitation $(\mathrm{LOQ})=0.26 \mu \mathrm{g} / \mathrm{mL}$ ), silychristin ( $\left.\mathrm{y}=2266.4-12.7, \mathrm{R}^{2}=0.9994, \mathrm{LOD}=0.05 \mu \mathrm{g} / \mathrm{mL}, \mathrm{LOQ}=0.17 \mu \mathrm{g} / \mathrm{mL}\right)$, silydianin $\left(\mathrm{y}=1649.8+34.8, \mathrm{R}^{2}=0.9992, \mathrm{LOD}=0.10 \mu \mathrm{g} / \mathrm{mL}, \mathrm{LOQ}=0.32 \mu \mathrm{g} / \mathrm{mL}\right)$, silybin A $(\mathrm{y}=2575.0+$ $\left.5.7, \mathrm{R}^{2}=0.9997, \mathrm{LOD}=0.05 \mu \mathrm{g} / \mathrm{mL}, \mathrm{LOQ}=0.15 \mu \mathrm{g} / \mathrm{mL}\right)$, silybin $\mathrm{B}\left(\mathrm{y}=2515.9+27.3, \mathrm{R}^{2}=0.9999\right.$, $\mathrm{LOD}=0.05 \mu \mathrm{g} / \mathrm{mL}, \mathrm{LOQ}=0.15 \mu \mathrm{g} / \mathrm{mL})$, isosilybin $\mathrm{A}\left(\mathrm{y}=2726.3+17.8, \mathrm{R}^{2}=0.9998, \mathrm{LOD}=0.05 \mu \mathrm{g} / \mathrm{mL}\right.$, $\mathrm{LOQ}=0.16 \mu \mathrm{g} / \mathrm{mL})$, isosilybin B $\left(\mathrm{y}=2861.1+1.9, \mathrm{R}^{2}=0.9999, \mathrm{LOD}=0.05 \mu \mathrm{g} / \mathrm{mL}, \mathrm{LOQ}=0.16 \mu \mathrm{g} / \mathrm{mL}\right)$.

\subsection{Statistical Analysis}

All of the experiments were carried out in an organized manner, with each treatment examined thrice (biological replicates), and repeated twice (technical replicates). Origin (Windows v8.5) software (OriginLab Corporation, Wellesley Hills, MA, USA) was employed for statistical analysis and analytical data was revealed as mean \pm standard deviation with the help of Excel 2018 (Microsoft, Redmond, WA, USA).

\section{Conclusions}

In conclusion, melatonin with different light regimes strongly influences the biosynthesis of active ingredients in callus cultures of $S$. marianum. BAP and NAA in combination favors optimal callus induction from leaf explants. Moreover, continuous light $(24 \mathrm{~h})$ proved to be the most effective as an abiotic elicitor as compared to the rest of light regimes, whereas, higher melatonin concentrations have inhibitory effect on biomass accumulation and phytochemical biosynthesis. Additionally, continuous light with $1.0 \mathrm{mg} / \mathrm{L}$ melatonin is the best for enhanced total silymarin content $(11.92 \mathrm{mg} / \mathrm{g} \mathrm{DW})$ along with increased anti-inflammatory and antioxidant properties in S. marianum callus cultures, thus making silymarin clinically more attractive for these properties. Previously, the anti-inflammatory effect and antioxidant potential of silymarin in Type 2 diabetes patients have been demonstrated [82]. Similarly, silymarin has been reported to decrease the elevated levels of complement proteins and interleukins in patients with knee osteoarthritis, when used either alone or in conjunction with non-steroidal anti-inflammatory drugs [83]. The results of our study indicate that silybin (A and B) and silychristin are the major secondary metabolites produced in S. marianum callus cultures. Several experimental reports have indicated the metabolic, antioxidant and antifibrotic effects of silybin. Although earlier human studies lack adequate confirmation towards the clinical efficacy of silybin in chronic liver diseases, silybin seems to be a promising candidate in the management of chronic liver diseases on the basis of available literature and ongoing clinical trials [84]. Traditional cultivation of milk thistle plants is prone to many complications which results in reduced total yield, mainly due to the spiny nature of the flowers and leaves. Furthermore, using herbicides leads to contamination of the seeds (fruits) with toxins. To overcome these complications, an in vitro propagation system is extremely useful. This study helps to better comprehend the influence of melatonin and different light regimes on secondary metabolites production as well as antioxidant and anti-inflammatory activities in in vitro callus cultures of S. marianum and paves the way for the use of this production system for future nutraceutical or cosmeceutical applications. However, techniques like high-throughput 
sequencing are still required in order to elucidate the effect of melatonin and different light regimes on metabolic pathways underlying silymarin biosynthesis in S. marianum.

Author Contributions: Conceptualization, C.H. and B.H.A.; Methodology, M.S., S.D., M.A.U., M.Y. and D.T.; validation, C.H. and B.H.A.; formal analysis, C.H. and B.H.A.; investigation, M.S., M.Y., M.A.U., S.D. and D.T.; resources, B.H.A. N.G.-G. and C.H.; data curation, M.A.U., M.S. and M.Y.; writing-original draft preparation, M.S. and M.A.U.; writing-review and editing, C.H. and B.H.A.; visualization, M.S. and M.A.U.; supervision, C.H. and B.H.A.; project administration, N.G.-G., C.H. and B.H.A.; funding acquisition, B.H.A., N.G.-G. and C.H.

Funding: This research was supported by Cosmetosciences, a global training and research program dedicated to the cosmetic industry. Located in the heart of the Cosmetic Valley, this program led by University of Orléans is funded by the Région Centre-Val de Loire (MARILINE 16029ICO \& VALBIOCOSM 17019UNI). B.H.A. acknowledges research fellowship of Le Studium-Institute for Advanced Studies, Loire Valley, Orléans, France. S.D. acknowledges research fellowships of Loire Valley Region. D.T. gratefully acknowledges the support of French government via the French Embassy in Thailand in the form of Junior Research Fellowship Program 2018.

Conflicts of Interest: The authors declare no conflict of interest.

\section{References}

1. Abenavoli, L.; Izzo, A.A.; Milić, N.; Cicala, C.; Santini, A.; Capasso, R. Milk thistle (Silybum marianum): A concise overview on its chemistry, pharmacological, and nutraceutical uses in liver diseases. Phytother. Res. 2018, 32, 2202-2213. [CrossRef] [PubMed]

2. Khan, M.A.; Abbasi, B.H.; Ahmed, N.; Ali, H. Effects of light regimes on in vitro seed germination and silymarin content in Silybum marianum. Ind. Crops Prod. 2013, 46, 105-110. [CrossRef]

3. Soto, C.; Pérez, J.; García, V.; Uría, E.; Vadillo, M.; Raya, L. Effect of silymarin on kidneys of rats suffering from alloxan-induced diabetes mellitus. Phytomedicine 2010, 17, 1090-1094. [CrossRef] [PubMed]

4. Al-Anati, L.; Essid, E.; Reinehr, R.; Petzinger, E. Silibinin protects OTA-mediated TNF- $\alpha$ release from perfused rat livers and isolated rat Kupffer cells. Mol. Nutr. Food Res. 2009, 53, 460-466. [CrossRef]

5. Abbasi, B.H.; Stiles, A.R.; Saxena, P.K.; Liu, C.-Z. Gibberellic acid increases secondary metabolite production in Echinacea purpurea hairy roots. Appl. Biochem. Biotechnol. 2012, 168, 2057-2066. [CrossRef]

6. Abbasi, B.H.; Khan, M.; Guo, B.; Bokhari, S.A.; Khan, M.A. Efficient regeneration and antioxidative enzyme activities in Brassica rapa var. turnip. Plant Cell Tissue Organ. Cult. (PCTOC) 2011, 105, 337-344. [CrossRef]

7. Abbasi, B.H.; Tian, C.-L.; Murch, S.J.; Saxena, P.K.; Liu, C.-Z. Light-enhanced caffeic acid derivatives biosynthesis in hairy root cultures of Echinacea purpurea. Plant Cell Rep. 2007, 26, 1367-1372. [CrossRef] [PubMed]

8. Kaur, A.K.; Wahi, A.; Brijesh, K.; Bhandari, A.; Prasad, N. Milk thistle (Silybum marianum): A review. IJPRD 2011, 3, 1-10.

9. Polyak, S.J.; Ferenci, P.; Pawlotsky, J.M. Hepatoprotective and antiviral functions of silymarin components in hepatitis C virus infection. Hepatology 2013, 57, 1262-1271. [CrossRef] [PubMed]

10. Can, V.; Abouelnour, A.; Locke, I.; Bligh, S.; Getting, S. The effect of silymarin on chondrocytes. Biochem. Pharmacol. 2017, 139, 137. [CrossRef]

11. Qin, N.-b.; Jia, C.-c.; Xu, J.; Li, D.-h.; Xu, F.-x.; Bai, J.; Li, Z.-1.; Hua, H.-m. New amides from seeds of Silybum marianum with potential antioxidant and antidiabetic activities. Fitoterapia 2017, 119, 83-89. [CrossRef] [PubMed]

12. Shavandi, M.; Moini, A.; Shakiba, Y.; Mashkorinia, A.; Dehghani, M.; Asar, S.; Kiani, A. Silymarin (Livergol $\left.{ }^{\circledR}\right)$ decreases disease activity score in patients with rheumatoid arthritis: A non-randomized single-Arm clinical trial. Iran J. Allergy Asthma Immunol. 2017, 16, 99-106.

13. Grant, J.E.; Odlaug, B.L. Silymarin treatment of obsessive-compulsive spectrum disorders. J. Clin. Psychopharmacol. 2015, 35, 340-342. [CrossRef] [PubMed]

14. Colica, C.; Boccuto, L.; Abenavoli, L. Silymarin: An option to treat non-alcoholic fatty liver disease. World J. Gastroenterol. 2017, 23, 8437. [CrossRef] [PubMed]

15. Moayedi, B.; Gharagozloo, M.; Esmaeil, N.; Maracy, M.R.; Hoorfar, H.; Jalaeikar, M. A randomized double-blind, placebo-controlled study of therapeutic effects of silymarin in $\beta$-thalassemia major patients receiving desferrioxamine. Eur. J. Haematol. 2013, 90, 202-209. [CrossRef]

16. Mohale, D.; Tripathi, A.; Wahane, J.; Chandewar, A. A Pharmacological Review on Cyclooxygenase Enzyme. Ind. J. Pharm. Pharmacol. 2014, 1, 46-58. 
17. Tungmunnithum, D.; Thongboonyou, A.; Pholboon, A.; Yangsabai, A. Flavonoids and other phenolic compounds from medicinal plants for pharmaceutical and medical aspects: An overview. Medicines 2018, 5, 93. [CrossRef]

18. Tajmohammadi, A.; Razavi, B.M.; Hosseinzadeh, H. Silybum marianum (milk thistle) and its main constituent, silymarin, as a potential therapeutic plant in metabolic syndrome: A review. Phytother Res. 2018, 32, 1933-1949. [CrossRef]

19. Szopa, A.; Dziurka, M.; Warzecha, A.; Kubica, P.; Klimek-Szczykutowicz, M.; Ekiert, H. Targeted lignan profiling and anti-inflammatory properties of Schisandra rubriflora and Schisandra chinensis extracts. Molecules 2018, 23, 3103. [CrossRef]

20. Borges, A.; Casoti, R.; e Silva, M.L.A.; da Cunha, N.L.; da Rocha Pissurno, A.P.; Kawano, D.F.; da Silva de Laurentiz, R. COX Inhibition Profiles and Molecular Docking Studies of the Lignan Hinokinin and Some Synthetic Derivatives. Mol. Inform. 2018, 37, 1800037. [CrossRef]

21. Baenas, N.; García-Viguera, C.; Moreno, D.A. Elicitation: A tool for enriching the bioactive composition of foods. Molecules 2014, 19, 13541-13563. [CrossRef]

22. Narayani, M.; Srivastava, S. Elicitation: A stimulation of stress in in vitro plant cell/tissue cultures for enhancement of secondary metabolite production. Phytochem. Rev. 2017, 16, 1227-1252. [CrossRef]

23. Gupta, S.D.; Jatothu, B. Fundamentals and applications of light-emitting diodes (LEDs) in in vitro plant growth and morphogenesis. Plant Biotechnol. Rep. 2013, 7, 211-220. [CrossRef]

24. Hughes, K.W. In vitro ecology: Exogenous factors affecting growth and morphogenesis in plant culture systems. Environ. Exp. Bot. 1981, 21, 281-288. [CrossRef]

25. Lerner, A.B.; Case, J.D.; Takahashi, Y.; Lee, T.H.; Mori, W. Isolation of melatonin, the pineal gland factor that lightens melanocyteS1. J. Am. Chem. Soc. 1958, 80, 2587. [CrossRef]

26. Cao, J.; Murch, S.J.; O’Brien, R.; Saxena, P.K. Rapid method for accurate analysis of melatonin, serotonin and auxin in plant samples using liquid chromatography-tandem mass spectrometry. J. Chromatogr. A 2006, 1134, 333-337. [CrossRef] [PubMed]

27. Dubbels, R.; Reiter, R.; Klenke, E.; Goebel, A.; Schnakenberg, E.; Ehlers, C.; Schiwara, H.; Schloot, W. Melatonin in edible plants identified by radioimmunoassay and by high performance liquid chromatography-mass spectrometry. J. Pineal. Res. 1995, 18, 28-31. [CrossRef] [PubMed]

28. Kolář, J.; Macháčková, I. Melatonin in higher plants: Occurrence and possible functions. J. Pineal. Res. 2005, 39, 333-341. [CrossRef] [PubMed]

29. Manchester, L.C.; Tan, D.-X.; Reiter, R.J.; Park, W.; Monis, K.; Qi, W. High levels of melatonin in the seeds of edible plants: Possible function in germ tissue protection. Life Sci. 2000, 67, 3023-3029. [CrossRef]

30. Arnao, M.B.; Hernández-Ruiz, J. Melatonin promotes adventitious-and lateral root regeneration in etiolated hypocotyls of Lupinus albus L. J. Pineal. Res. 2007, 42, 147-152. [CrossRef] [PubMed]

31. Hernandez-Ruiz, J.; Cano, A.; Arnao, M.B. Melatonin: A growth-stimulating compound present in lupin tissues. Planta 2004, 220, 140-144. [CrossRef] [PubMed]

32. Murch, S.J.; Saxena, P.K. Melatonin: A potential regulator of plant growth and development? In Vitro Cell Dev. Biol. Plant. 2002, 38, 531-536. [CrossRef]

33. Kolář, J.; Johnson, C.H.; Macháčková, I. Exogenously applied melatonin (N-acetyl-5-methoxytryptamine) affects flowering of the short-day plant Chenopodium rubrum. Physiol. Plant 2003, 118, 605-612. [CrossRef]

34. Pelagio-Flores, R.; Muñoz-Parra, E.; Ortiz-Castro, R.; López-Bucio, J. Melatonin regulates Arabidopsis root system architecture likely acting independently of auxin signaling. J. Pineal. Res. 2012, 53, 279-288. [CrossRef] [PubMed]

35. Wolf, K.; Kolář, J.; Witters, E.; van Dongen, W.; van Onckelen, H.; Macháčková, I. Daily profile of melatonin levels in Chenopodium rubrum L. depends on photoperiod. J. Plant Physiol. 2001, 158, 1491-1493. [CrossRef]

36. Fankhauser, C.; Chory, J. Light control of plant development. Annu. Rev. Cell Dev. Biol. 1997, 13, $203-229$. [CrossRef] [PubMed]

37. Wei, W.; Li, Q.T.; Chu, Y.N.; Reiter, R.J.; Yu, X.M.; Zhu, D.H.; Zhang, W.K.; Ma, B.; Lin, Q.; Zhang, J.S.; et al. Melatonin enhances plant growth and abiotic stress tolerance in soybean plants. J. Exp. Bot. 2014, 66, 695-707. [CrossRef] [PubMed]

38. Zhang, N.; Sun, Q.; Zhang, H.; Cao, Y.; Weeda, S.; Ren, S.; Guo, Y.D. Roles of melatonin in abiotic stress resistance in plants. J. Exp. Bot. 2014, 66, 647-656. [CrossRef] 
39. Fazal, H.; Abbasi, B.H.; Ahmad, N.; Ali, M. Exogenous melatonin trigger biomass accumulation and production of stress enzymes during callogenesis in medicinally important Prunella vulgaris L. (Selfheal). Physiol. Mol. Biol. Plants. 2018, 24, 1307-1315. [CrossRef]

40. Khan, T.; Ullah, M.A.; Garros, L.; Hano, C.; Abbasi, B.H. Synergistic effects of melatonin and distinct spectral lights for enhanced production of anti-cancerous compounds in callus cultures of Fagonia indica. J. Photochem. Photobiol. B 2018. [CrossRef] [PubMed]

41. Adil, M.; Abbasi, B.H.; Khan, T. Interactive effects of melatonin and light on growth parameters and biochemical markers in adventitious roots of Withania somnifera L. Plant Cell Tissue Organ Cult. (PCTOC) 2015, 123, 405-412. [CrossRef]

42. Tan, J.; Bednarek, P.; Liu, J.; Schneider, B.; Svatoš, A.; Hahlbrock, K. Universally occurring phenylpropanoid and species-specific indolic metabolites in infected and uninfected Arabidopsis thaliana roots and leaves. Phytochemistry 2004, 65, 691-699. [CrossRef] [PubMed]

43. Ali, M.B.; Khatun, S.; Hahn, E.-J.; Paek, K.-Y. Enhancement of phenylpropanoid enzymes and lignin in Phalaenopsis orchid and their influence on plant acclimatisation at different levels of photosynthetic photon flux. Plant Growth Regul. 2006, 49, 137-146. [CrossRef]

44. Sarrou, E.; Chatzopoulou, P.; Dimassi-Theriou, K.; Therios, I.; Koularmani, A. Effect of melatonin, salicylic acid and gibberellic acid on leaf essential oil and other secondary metabolites of bitter orange young seedlings. J. Essent. Oil Res. 2015, 27, 487-496. [CrossRef]

45. Ellis, R.; Roberts, E. Towards a rational basis for testing seed quality. Proc.-Easter Sch. Agric. Sci. Univ. Nottm. 1978, 605-635.

46. Senger, H. Blue Light Responses: Phenomena and Occurrence in Plants and Microorganisms; CRC Press: Boca Raton, FL, USA, 1987.

47. Zhong, J.J.; Seki, T.; Kinoshita, S.i.; Yoshida, T. Effect of light irradiation on anthocyanin production by suspended culture of Perilla frutescens. Biotechnol. Bioeng. 1991, 38, 653-658. [CrossRef] [PubMed]

48. Beckwith, A.G.; Zhang, Y.; Seeram, N.P.; Cameron, A.C.; Nair, M.G. Relationship of light quantity and anthocyanin production in Pennisetum setaceum cvs. Rubrum and Red Riding Hood. J. Agric. Food. Chem. 2004, 52, 456-461. [CrossRef] [PubMed]

49. Moran, J.F.; Becana, M.; Iturbe-Ormaetxe, I.; Frechilla, S.; Klucas, R.V.; Aparicio-Tejo, P. Drought induces oxidative stress in pea plants. Planta 1994, 194, 346-352. [CrossRef]

50. Alexieva, V.; Sergiev, I.; Mapelli, S.; Karanov, E. The effect of drought and ultraviolet radiation on growth and stress markers in pea and wheat. Plant Cell Environ. 2001, 24, 1337-1344. [CrossRef]

51. Yu, T.-W.; Anderson, D. Reactive oxygen species-induced DNA damage and its modification: A chemical investigation. Mutat. Res. Fund. Mol. M 1997, 379, 201-210. [CrossRef]

52. Mittler, R. Oxidative stress, antioxidants and stress tolerance. Trends Plant Sci. 2002, 7, 405-410. [CrossRef]

53. Ashry, N.A.; Mohamed, H.I. Impact of secondary metabolites and related enzymes in flax resistance and or susceptibility to powdery mildew. World J. Agric. Sci 2011, 7, 78-85.

54. Samuolienè, G.; Brazaitytè, A.; Urbonavičiūtè, A.; Šabajevienè, G.; Duchovskis, P. The effect of red and blue light component on the growth and development of frigo strawberries. Zemdirbyste Agric. 2010, 97, 99-104.

55. Basaga, H.; Poli, G.; Tekkaya, C.; Aras, I. Free radical scavenging and antioxidative properties of 'silibin'complexes on microsomal lipid peroxidation. Cell Biochem. Func. 1997, 15, 27-33. [CrossRef]

56. Zahir, A.; Abbasi, B.H.; Adil, M.; Anjum, S.; Zia, M. Synergistic effects of drought stress and photoperiods on phenology and secondary metabolism of Silybum marianum. Appl. Biochem. Biotechnol. 2014, 174, 693-707. [CrossRef]

57. Lettéron, P.; Labbe, G.; Degott, C.; Berson, A.; Fromenty, B.; Delaforge, M.; Larrey, D.; Pessayre, D. Mechanism for the protective effects of silymarin against carbon tetrachloride-induced lipid peroxidation and hepatotoxicity in mice: Evidence that silymarin acts both as an inhibitor of metabolic activation and as a chain-breaking antioxidant. Biochem. Pharmacol. 1990, 39, 2027-2034. [CrossRef]

58. Djeridane, A.; Yousfi, M.; Nadjemi, B.; Boutassouna, D.; Stocker, P.; Vidal, N. Antioxidant activity of some Algerian medicinal plants extracts containing phenolic compounds. Food Chem. 2006, 97, 654-660. [CrossRef]

59. Kim, D.-O.; Chun, O.K.; Kim, Y.J.; Moon, H.-Y.; Lee, C.Y. Quantification of polyphenolics and their antioxidant capacity in fresh plums. J. Agric. Food. Chem. 2003, 51, 6509-6515. [CrossRef] [PubMed]

60. Rathee, P.; Chaudhary, H.; Rathee, S.; Rathee, D.; Kumar, V.; Kohli, K. Mechanism of action of flavonoids as anti-inflammatory agents: A review. Inflamm. Allergy Drug Targets 2009, 8, 229-235. [CrossRef] [PubMed] 
61. Gupta, O.; Sing, S.; Bani, S.; Sharma, N.; Malhotra, S.; Gupta, B.; Banerjee, S.; Handa, S. Anti-inflammatory and anti-arthritic activities of silymarin acting through inhibition of 5-lipoxygenase. Phytomedicine 2000, 7 , 21-24. [CrossRef]

62. Aghazadeh, S.; Amini, R.; Yazdanparast, R.; Ghaffari, S.H. Anti-apoptotic and anti-inflammatory effects of Silybum marianum in treatment of experimental steatohepatitis. Exp. Toxicol. Pathol. 2011, 63, 569-574. [CrossRef] [PubMed]

63. Shaker, E.; Mahmoud, H.; Mnaa, S. Silymarin, the antioxidant component and Silybum marianum extracts prevent liver damage. Food Chem. Toxicol. 2010, 48, 803-806. [CrossRef]

64. Pradhan, S.; Girish, C. Hepatoprotective herbal drug, silymarin from experimental pharmacology to clinical medicine. Indian J. Med. Res. 2006, 124, 491-504.

65. Guo, L.Y.; Hung, T.M.; Bae, K.H.; Shin, E.M.; Zhou, H.Y.; Hong, Y.N.; Kang, S.S.; Kim, H.P.; Kim, Y.S. Anti-inflammatory effects of schisandrin isolated from the fruit of Schisandra chinensis Baill. Eur. J. Pharmacol. 2008, 591, 293-299. [CrossRef] [PubMed]

66. Lim, Z.X.; Ling, A.P.K.; Hussein, S. Callus induction of Ocimum sanctum and estimation of its total flavonoids content. Asian J. Agric. Sci. 2009, 1, 55-61.

67. Hackett, E.; Twedt, D.; Gustafson, D. Milk thistle and its derivative compounds: A review of opportunities for treatment of liver disease. J. Vet. Intern. Med. 2013, 27, 10-16. [CrossRef]

68. Surai, P. Silymarin as a natural antioxidant: An overview of the current evidence and perspectives. Antioxidants 2015, 4, 204-247. [CrossRef] [PubMed]

69. Althagafy, H.S.; Meza-Aviña, M.E.; Oberlies, N.H.; Croatt, M.P. Mechanistic study of the biomimetic synthesis of flavonolignan diastereoisomers in milk thistle. J. Org. Chem. 2013, 78, 7594-7600. [CrossRef] [PubMed]

70. Shiga, T.; Shoji, K.; Shimada, H.; Hashida, S.-n.; Goto, F.; Yoshihara, T. Effect of light quality on rosmarinic acid content and antioxidant activity of sweet basil, Ocimum basilicum L. Plant Biotechnol. 2009, 26, 255-259. [CrossRef]

71. Nadeem, M.; Abbasi, B.H.; Younas, M.; Ahmad, W.; Zahir, A.; Hano, C. LED-enhanced biosynthesis of biologically active ingredients in callus cultures of Ocimum basilicum. J. Photochem. Photobiol. B 2018. [CrossRef]

72. Younas, M.; Drouet, S.; Nadeem, M.; Giglioli-Guivarc'h, N.; Hano, C.; Abbasi, B.H. Differential accumulation of silymarin induced by exposure of Silybum marianum L. callus cultures to several spectres of monochromatic lights. J. Photochem. Photobiol. B 2018, 184, 61-70. [CrossRef] [PubMed]

73. Merlini, L.; Zanarotti, A.; Pelter, A.; Rochefort, M.P.; Hänsel, R. Benzodioxans by oxidative phenol coupling. Synthesis of silybin. J. Chem. Soc. Perkin Trans. 1 1980, 775-778. [CrossRef]

74. Poppe, L.; Petersen, M. Variation in the flavonolignan composition of fruits from different Silybum marianum chemotypes and suspension cultures derived therefrom. Phytochemistry 2016, 131, 68-75. [CrossRef]

75. Murashige, T.; Skoog, F. A revised medium for rapid growth and bio assays with tobacco tissue cultures. Physiol. Plant. 1962, 15, 473-497. [CrossRef]

76. Singleton, V.L.; Rossi, J.A. Colorimetry of total phenolics with phosphomolybdic-phosphotungstic acid reagents. Am. J. Enol. Vitic. 1965, 16, 144-158.

77. Ahmad, N.; Fazal, H.; Abbasi, B.H.; Rashid, M.; Mahmood, T.; Fatima, N. Efficient regeneration and antioxidant potential in regenerated tissues of Piper nigrum L. Plant Cell Tissue Organ. Cult. 2010, 102, 129-134. [CrossRef]

78. Abbasi, B.H.; Khan, M.A.; Mahmood, T.; Ahmad, M.; Chaudhary, M.F.; Khan, M.A. Shoot regeneration and free-radical scavenging activity in Silybum marianum L. Plant. Cell Tissue Organ. Cult. 2010, 101, 371-376. [CrossRef]

79. Benzie, I.F.; Strain, J.J. The ferric reducing ability of plasma (FRAP) as a measure of "antioxidant power": The FRAP assay. Anal. Biochem. 1996, 239, 70-76. [CrossRef] [PubMed]

80. Velioglu, Y.; Mazza, G.; Gao, L.; Oomah, B. Antioxidant activity and total phenolics in selected fruits, vegetables, and grain products. J. Agric. Food Chem. 1998, 46, 4113-4117. [CrossRef]

81. Drouet, S.; Abbasi, B.; Falguières, A.; Ahmad, W.; Ferroud, C.; Doussot, J.; Vanier, J.; Lainé, E.; Hano, C. Single laboratory validation of a quantitative core shell-based LC separation for the evaluation of silymarin variability and associated antioxidant activity of pakistani ecotypes of milk thistle (Silybum marianum L.). Molecules 2018, 23, 904. [CrossRef] 
82. Gargari, B.P.; Mobasseri, M.; Valizadeh, H.; Asghari-Jafarabadi, M. Effects of Silybum marianum (L.) Gaertn. (silymarin) extract supplementation on antioxidant status and hs-CRP in patients with type 2 diabetes mellitus: A randomized, triple-blind, placebo-controlled clinical trial. Phytomedicine 2015, 22, 290-296.

83. Hussain, S.A.; Jassim, N.A.; Numan, I.T.; Al-Khalifa, I.I.; Abdullah, T.A. Anti-inflammatory activity of silymarin in patients with knee osteoarthritis. A comparative study with piroxicam and meloxicam. Saudi Med. J. 2009, 30, 98-103. [PubMed]

84. Loguercio, C.; Festi, D. Silybin and the liver: From basic research to clinical practice. World J. Gastroenterol. 2011, 17, 2288. [CrossRef] [PubMed]

Sample Availability: Plant materials and chemical standards used in the present study are available upon request to corresponding authors.

(C) 2019 by the authors. Licensee MDPI, Basel, Switzerland. This article is an open access article distributed under the terms and conditions of the Creative Commons Attribution (CC BY) license (http://creativecommons.org/licenses/by/4.0/). 